\title{
Creativity and Organizational Learning as Means to Foster Sustainability
}

Rodrigo Lozano* Sustainability Research Institute, School of Earth and Environment, University of Leeds, UK

\begin{abstract}
This article argues that creativity and organizational learning can help to challenge the traditional Newtonian and Cartesian mental models and foster more sustainable societies. The recognition and acceptance of creativity by individuals, groups, organizations, and finally society can create new knowledge and metanoia. Creativity helps to break through the knowledge barrier of current reductionist mental models, while learning helps to consolidate and institutionalize the new mental models. This is especially the case where learning questions underlying assumptions and develops new theories and methodologies that constantly challenge the status quo for the present and the future, instead of mere reaction to immediate problems. Eventually, these mental models would need to be questioned by future creative thinkers in a continuous process; hence, solving today's problems with tomorrow's ideas, and ensuring progress towards more sustainable societies. The paper takes the example of Gaia theory to illustrate how creativity can be institutionalized. Copyright (C) 2011 John Wiley \& Sons, Ltd and ERP Environment
\end{abstract}

Received 10 July 2011; revised 21 September 2011; accepted 19 October 2011

Keywords: creativity; Gaia theory; mental models; organizational learning; paradigm change; sustainability

\section{Introduction}

'Existing mental models - of managers, politicians, consumers, of everybody - influence to a large part the decisions being made and therefore these models are part of the problem itself. The 'unlearning' of old models and the provision of new ones are part of the solution.' (Rosner, I995)

$\mathrm{M}$ UCH OF MODERN EDUCATION AND PRAXIS HAS RELIED ON NEWTONIAN AND CARTESIAN MENTAL MODELS, WHICH are based on rationality, causality, mechanistic interpretation, silo thinking, and reductionism (Ketola, 2009; Lovelock, 2007; Nonaka and Takeuchi, 200I). These mental models have resulted in unprecedented advances in development and industrialization (Dunphy et al., 2003; Jensen, I993). However, such reliance on rationality, while neglecting and ignoring emotions (Henry, 200I), has resulted in a civilization crisis that confronts us with an unsustainable present and a threatened future (Carley and Christie, 2000; Haberl et al., 20II; Reid, I995).

A paradigm revolution is needed to break through existing knowledge barriers and current unsustainable mental models, and foster metanoia ${ }^{2}$ for sustainability. New ways of learning are needed, which actively and consciously

*Correspondence to: Dr Rodrigo Lozano, Sustainability Research Institute, School of Earth and Environment, University of Leeds, LS2 9JT, Leeds, UK.E-mail: R.Lozano@leeds.ac.uk

${ }^{\mathrm{I}}$ Mental models (such as schemata, paradigms, perspectives, beliefs, and viewpoints) help individuals to perceive and define their world (Nonaka and Takeuchi, 200I)

${ }^{2}$ Metanoia is a shift of mind-set or lifestyle (Senge, I999) 
engage in the use and protection of natural resources, and the safeguarding and improvement of societal well-being, for this generation and future ones (see Burke, 2000; Cortese, 2003; Rosner, I995). This revolution has to be based on holism, i.e. examining a thing from outside and asking questions while it works (Lovelock, 2007), transdisciplinarity (Brown et al., 2010), system thinking (Bagheri and Hjorth, 2007) and long-term thinking (WCED, I987).

This article proposes that creativity, when adopted by individuals, groups, organizations, and society, can help to challenge current unsustainable mental models. The article also discusses how organizational learning can help to question current underlying assumptions and norms, and subsequently institutionalize and consolidate these new mental models. This would, then, help to generate knowledge that would foster metanoia and more sustainable societies. Eventually, these mental models would need to be questioned by future creative thinkers in a continuous process.

\section{'Eureka', New Organizational Mental Models}

Of the myriad of human abilities, abstract thinking and creativity may be two of the most powerful and useful ways in which humans overcome ignorance and regain awareness by generating and institutionalizing new mental models for sustainability.

Creativity has been defined by a number of authors. Some propose that it is the ability to solve problems that one has not previously learned to solve (Mayer, I989). Others argue that it is about producing work that is novel and appropriate (Amabile, I983; Sternberg and Lubart, I999), arising from individuals working together in a complex mosaic of individual, group, and organizational characteristics and interactions (Woodman et al., I993). Novelty itself does not constitute a sufficient condition for defining creativity (Kaufmann, 200I). For others, it involves a change in memes ${ }^{3}$ (e.g. Csikszentmihalyi, 200I). Creativity could therefore be said to be the action of producing something novel and appropriate (for example a theory, method, or technology) that involves meme transfer throughout organizations and society.

In general, the seed for creativity, and the development of new mental models and theories, results from recognizing anomalies in phenomena that cannot be assimilated into existing mental models ${ }^{4}$ (Kuhn, I970), i.e. challenging the status quo of industries and management approaches (Hailey, I998).

Sternberg (2006) proposes eight types of creativity, grouped into three categories, and explains how they relate to paradigms: (i) types that accept current paradigms and attempts to extend them (including replication, forward incrementation and advance forward incrementation); (ii) types that reject current paradigms and attempt to replace them (redirection, reconstruction/redirection and reinitiation); and (iii) a type of creativity that synthesizes current paradigms (integration). The second and third groups challenge the status quo. An interesting perspective is offered by the third type, where mental models, that may or may not be conflicting, are combined to suggest holistic solutions.

\section{Transferring Creativity From Individuals To Societies}

Understanding creativity involves comprehending (i) the creative process, (ii) the creative product, (iii) the creative person, (iv) the creative situation, and (v) the way in which each of these components interacts with the others in a social system. Social systems include a complex mosaic of individual, groups, with organizational characteristics and interactions (Woodman et al., I993).

Different traits, processes, and models have been proposed to help explain the creative person, or individual creativity. Woodman et al. (I993) indicate that many researchers have postulated intrinsic motivational orientation

${ }^{3}$ Dawkins (I978) defines 'meme' as '. . . a noun which conveys the idea of a unit of cultural transmission, or a unit of imitation.'

${ }^{4}$ Although Kuhn (I970) and Sternberg (2006) use the term paradigm, in this paper the term mental models is used because it encompasses paradigms, schemata, perspectives, beliefs and viewpoints (Nonaka and Takeuchi, 200I) 
as a key element in creativity, in addition to contextual social influences and antecedent conditions. For example, Sternberg and Lubart (I999) indicate that traditionally, creativity has been associated with mystical beliefs, e.g. the creative person as an empty vessel that a divine being would fill with inspiration, and then the individual would pour out the inspired idea. Amabile (1983) proposes persistence, curiosity, energy, and intellectual honesty as creativity traits. Carrol (1985; cited by Woodman et al., I993) proposes eight factors: seven relating to fluency: associative, of expression, figural, ideational, speech, word, and practical ideational; and originality. Shaw (I989, p. 297) indicates that creativity is a human process that involves deep feelings. Therefore, it can be argued that individual creativity links synergistically the cognitive to the intrinsic, non-cognitive, emotional processes, i.e. rationality and science meet emotions and art.

Basadur et al. (1982) propose that creativity follows a sequential application of divergent thinking (ideation) and convergent thinking (problem finding, solution generation and solution implementation). McNally (I982) indicates that individual creativity follows five stages: immersion (involving the experiential inputs from internal and external sources); incubation (the unconscious development of the process); illumination (the moment or phase when the pieces of the puzzle fall into place, the Eureka moment); explication (the phase of self-explanation); and creative synthesis (when the full nature of the experience is revealed). The first three stages encompass Basadur et al.'s (I982) flow. Sternberg (2006) argues that individual creativity flows from the generation of new ideas, to their analysis, and finally to selling the ideas to others. According to this theory, creativity is in large partly a decision where unknown or out-of-favour ideas are pursued where growth potential is expected. Six distinct but inter-related resources must come together for this process: intellectual abilities, knowledge, styles of thinking, personality, motivation, and environment. Of the three models, McNally's (I982) provides the most comprehensive clarification of the creativity process, but it can be complemented with Sternberg's (2006) model, by 'selling the idea to others'. If the idea is not externalized, whether through written or oral communication, it will disappear with the demise of its creator.

From the above discussion it can be argued that creativity occurs when cognitive and non-cognitive traits (emotion and rationality) interact synergistically through divergent and convergent thinking. This leads to a 'Eureka' moment, the synthesis of the idea, and the possibility of communicating it to others.

Individuals do not, usually, live in isolation. They interact by sharing values and norms to create and join groups (2008; Luthans, 2002). Creativity and the changes it involves cannot be adopted unless they are sanctioned by some group (Csikszentmihalyi, 200I), or some powerful or influential leader. When creativity is used long enough and increasingly by the different members of a group or organization until stabilization, then a point is reached where it becomes part of the culture of the institution, i.e. it is institutionalized (Rogers, I995; Sherry, 2003). Woodman et al. (I993) posit that group creativity is a function of individual creativity, the interaction of individuals, group characteristics (e.g. norms, size, degree of cohesiveness), group processes (e.g. approaches to problem solving), and contextual influences (e.g. the larger organization, characteristics of group task). Group creativity is more than the simple aggregate of all group members' creativity, although it is a function of the creativity of the group's members.

In the process of institutionalizing creativity into groups, opinion leaders (or change agents) play an influential role in initiating, transferring and encouraging it (Rogers, I995; Sherry, 2003). Figure I underscores the importance of working with change agents, innovators, and opinion leaders to push for change in an organization; hence catalysing and speeding up the adoption of new ideas (Lozano, 2006), or memes.

Similar to group creativity, organizational creativity is a function of the creative outputs of its component groups and contextual influences (organizational culture, reward systems, resource constraints, the larger environment outside the system, and so on) (Woodman et al., I993). The unconscious processes of groups and organizations mould

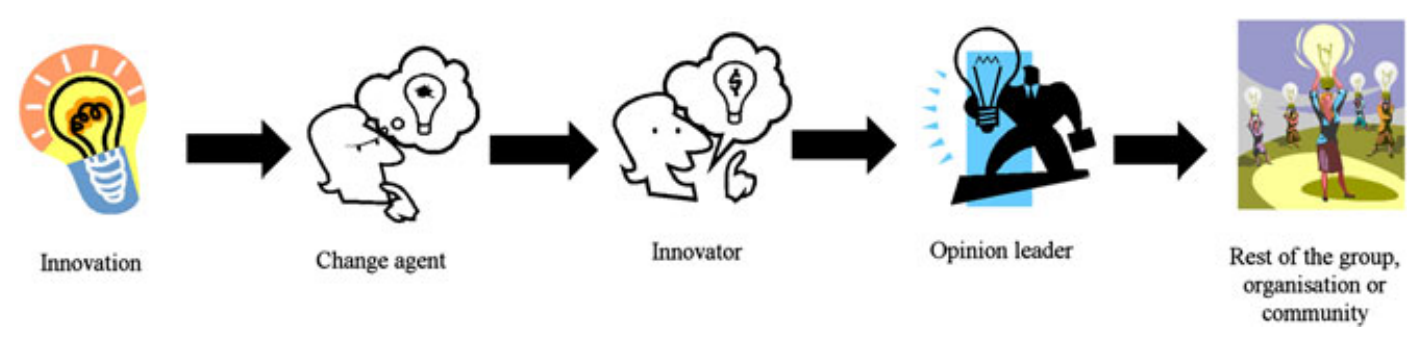

Figure 1. Generation and transfer of new ideas and memes. Source: (Lozano, 2006) 
those of their members (Gabriel, 200I), where organizations have the ability to acquire and deduce new knowledge and information from the inside out, and not simply process external information (Nonaka and Takeuchi, 200I).

Once creativity has been accepted in the organization, it might then be transferred to society. Some examples of this are the classical Greek period, the Italian Renaissance, the American Revolution, and the years since the mid-nineteenth century (with the contributions of numerous Jewish geniuses), where social creativity was also enhanced by environmental factors (Arieti, I976). The Renaissance was a particularly exciting time where creativity was an amalgam of science and the arts (J. D. Bernal quoted by A. Brown, 2005), with polymaths such as Leonardo da Vinci, Michelangelo, and Raphael, and individuals and families, such as Ludovico Sforza, the Medicis, and even the Borgias, who provided financial support and encouragement for the marriage of rationality and emotions.

Creativity and 'Eureka' moments can, therefore, help to break the knowledge barrier that is currently blocking movement forward to more sustainable societies. 'Eureka' moments need to be endorsed by groups, organizations and society (societal metanoia), so that creativity may be institutionalized, and the knowledge consolidated. Creativity, once accepted by groups, organizations and finally society, leads to the emergence of new more sustainable mental models. Once the transition to the new paradigm is complete (Kuhn, I970), then the new paradigm can be said to have been institutionalized (Lozano, 2006; Rogers, I995; Sherry, 2003). Support mechanisms can help to foster the connection of the cognitive and non-cognitive traits of individuals. The institutionalization might not be a clear cut break from previous mental models, because when a new paradigm is created, the older schools gradually disappear, in part as the result of the new generation adopting it and in part to some of the previous generation converting (Kuhn, I970). Nonetheless, there would still be some who cling to the older paradigm. This process is presented in Figure 2.

\section{Towards Discerning and Inquisitive Learning}

For creativity to be transferred from individuals to society, the process of learning must take place. Learning is recognized as a key skill to achieve sustainable development, as shown in Table I, and new circumstances and unpredictable change (Hailey, I998). Constant learning helps to change mental models and behaviour (Clarke and Roome, I999; Doppelt, 2003; 2008; Senge, I999), and to cope with new circumstances and change (Hailey, I998). It is a '... a building block for long-term success on the path toward sustainability' (Doppelt, 2003), and plays a key role in transferring creative ideas from individuals to society.

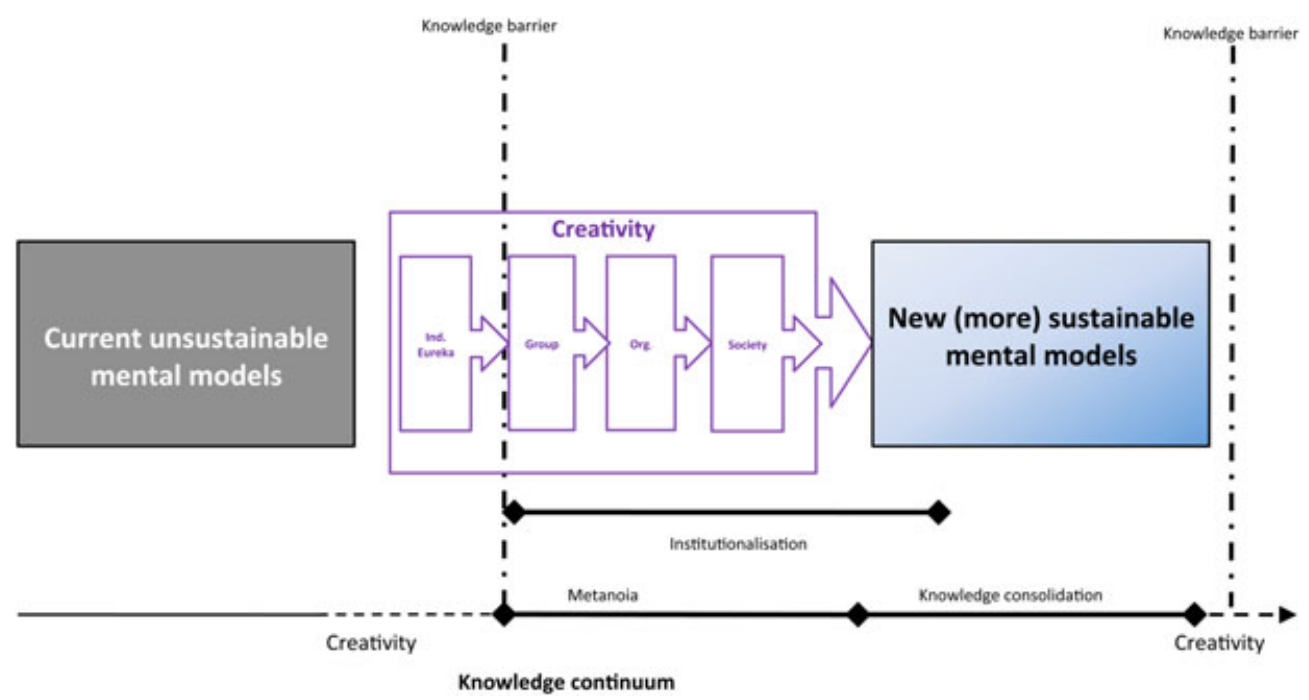

Figure 2. Creativity as a mechanism to move towards new more sustainable mental models 
Recognition of the challenge

Collective responsibility and constructive partnership

Acting with determination

The indivisibility of human dignity
Learning to know

Learning to live together

Learning to do

Learning to be

Table 1. Aspects provided by education to solve the requirements of SD

Source: Adapted from UNESCO (2003)

Learning ${ }^{5}$ refers to an increase in knowledge through teaching, life experiences (Penrose, I959), problem-solving (Kuhn, I970), and from theories (Rosner, I995). It involves cognitive, emotional, and physical dimensions, for those who are willing to risk it (Lessard and Amsden, I996; Orr, I992; Rosner, I995). Learning can also be defined as the process of acquiring knowledge, then creating and refining mental models (Penrose, I959; Rosner, I995; Schein, I969). Learning is increased when the individual asks intelligent questions about the observed world, and then looks for answers - testing of hypotheses and theory forming. There is not an unbridgeable dichotomy between asking questions and looking for answers. Learning is contingent rather than deterministic (Lessard and Amsden, I996), i.e. it depends not only on opportunities to learn, but also on costly investments to exploit such opportunities.

As with creativity, learning occurs in units: individuals, groups, organizations and society.

Individual learning comprises managing mental models by passing through a temporal process to expose assumptions, examining their consistency and accuracy, and seeing how different models can be brought together (Argyris, I977; Rosner, I995; Senge, I999). In some cases, individual learning induces, but not necessarily guarantees, organizational learning (Senge, I999). Most commonly, individual learning induces group learning, which then is disseminated throughout the organization (2008; Senge, 1999).

In group learning or team learning, individuals collaborate to learn (2008; Senge, I999). The combined intelligence in the team exceeds the sum of the intelligence of its individuals, and the team develops extraordinary capacities for collaborative action (Basadur et al., I986; Senge, I999; Woodman, et al., I993). Group learning plays a significant role in developing or modifying mental models (Mohammed and Dumville, 200I).

Organizational learning for sustainable development is a complex and iterative process (Zadek, 2004) where organizations acquire knowledge through an experiential process about action-outcome relationships, and the effects of the environment upon these (van de Ven et al., I999). Organizations have the potential to learn from their successes and from their mistakes (McIntosh et al., I998). Even though organizations learn all the time (Lessard and Amsden, I996), learning can be hindered by bureaucracy (Gill, 2003).

According to Senge (I999) organizations learn through individuals, where learning new skills and implementing institutional creativity helps to develop the organization's capacity to work with mental models, and key decisions are made based on shared understandings of inter-relationships and patterns of change. In this context, the boundaries between personal and organizational are intentionally blurred. 2008 complements Senge (I999) by indicating that individual learning can facilitate group learning, which in turn facilitates organizational learning. Organizational learning, in turn, facilitates group learning, and this in turn facilitates individual learning. Senge (I999) also argues that congruence plays a key role in this process. In many cases, lack of congruence results in frustration, dissatisfaction, loss of control, and even sabotage of sustainability initiatives (2008).

In fostering societal metanoia, e.g. for sustainability, learning needs to consider the inter-linkages and alignment of individual, group, and organizational learning, and how these connect congruently with the emotions and behaviours in the system. This is addressed by 2008 Multi-dimensional Sustainability Influence Change (MuSIC) memework (see Figure 3), which argues that learning (informational attitudes) is interlinked with cognition and feeling (emotional attitudes), and these in turn with behaviour (behavioural attitudes). Therefore, learning is linked

${ }^{5}$ Learning is different from schooling and training. Schooling, according to Orr (I992), has to do with mastering basic functions measured by tests. Training refers to the inculcation of rote habits, the acquisition of skills (Lessard and Amsden, I996; Rosner, I995), and systematic instruction of a particular task. 


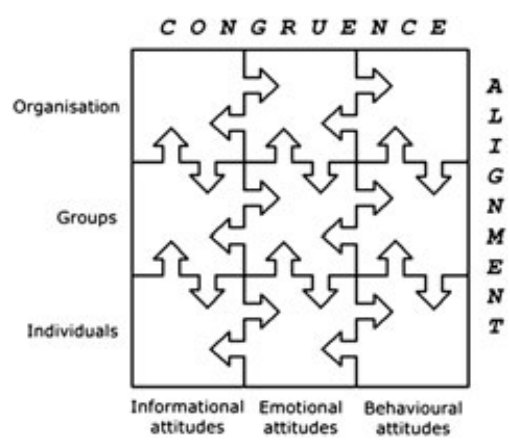

Figure 3. Multi-dimensional Sustainability Influence Change (MuSIC) memework. Source: (2008)

to emotions (as in the case of creativity), and in changing mindsets and behaviour, in the context of the complex interactions of individuals, groups, and the organization.

Traditionally, learning has been considered as following a linear path (Figure 4), where knowing is followed by understanding, and this in turn by application. This is the case with Bloom et al. (I956), who propose a taxonomy with the following order: knowledge, comprehension, application, analysis, synthesis, and evaluation. Posch and Steiner (2006) propose an alternative path, called circular learning, where application feeds back into knowing (Figure 5). Although circular learning is aimed at providing some continuity to learning, it does not consider potential feedback processes from understanding to knowing, or applying to understanding, as shown in the MuSIC memework.

Another perspective of learning involves the learning loops of Argyris (I977), divided into single-loop, doubleloop and triple-loop learning. Single-loop refers to organizations detecting and correcting errors, to carry on with present policies, or to achieve objectives, i.e. comparing their performance to a set of pre-established standards, and making adjustments accordingly (Argyris, I977; Miller, I990). Single-loop learning usually focuses on solving present problems, but not querying whether the standard to be attained is appropriate or not. Many organizations have excelled at single-loop learning, which has led to the protection of primary loops (that inhibit learning), reinforcing each other (Argyris, I977). This encompasses the knowledge, comprehension and application of Bloom et al. (I956). Double-loop learning occurs when the underlying assumptions, norms, objectives, policies, goals and programmes are questioned, opened to confrontation, and submitted to comprehensive periodic reassessment against established standards, to ensure that they remain relevant (Argyris, I977; Miller, I990). It focuses on immediate

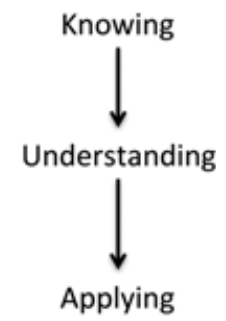

Figure 4. Linear learning. Source: (Posch and Steiner, 2006)

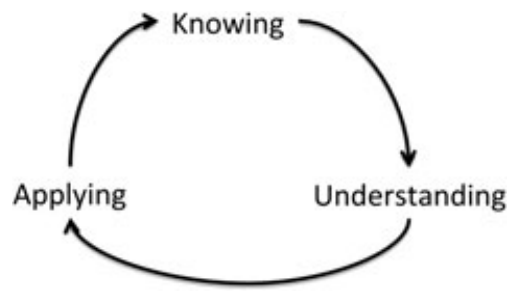

Figure 5. Circular learning. Source: (Posch and Steiner, 2006) 
problems, but delves deeper into the structure of the system to identify root causes, and it allows questioning of mental models and facilitates responses and changes with respect to the environment (Argyris, 1977). This encompasses Bloom et al.'s (I956) analysis, synthesis and evaluation. Triple-loop learning entails developing new processes, or methodologies, for arriving at such re-framings (Argyris, I977; Senge, I999; Waddel, 2005). While single-loop learning follows a linear path, the circular path is an integral part of double-loop and triple-loop learning.

Another typology for learning is proposed by Doppelt (2003) who separates learning into adaptive, anticipatory and action learning. Adaptive learning is a reactive, coping form of learning, which usually involves the search for direct solutions to immediate problems. Anticipatory learning focuses on avoiding future problems, by identifying potential events and searching for the best ways to prepare for them. It is more creative than adaptive learning. Action learning involves turning real problems or tasks into a learning laboratory, where teams seek to resolve problems and simultaneously, learn from their experiences.

The approaches taken by Argyris (I977) and Doppelt (2003) seem to be independent, yet complementary. This offers the possibility of combining them to offer a more complete typology that would consider the loops and the processes, as presented in Table 2, and is explained next.

Passive learning refers to increasing skills through schooling, where the purpose is to accomplish immediate tasks. No explanation for the task is provided or required. There is little or no concern for activities other than the particular tasks, or to other possible future tasks.

Forecasting learning refers to increasing skills in preparation for future tasks, events, or problems. No explanation for these is provided or even needed. Other activities that could possible affect the tasks or problems are not taken into consideration. The process relies on mental abstractions.

Coaching learning refers to increasing skills through training, where the purpose is to accomplish immediate or future tasks through real-life practical problem solving, a more 'hands-on' approach. As with passive learning and forecasting, no explanation for the task is provided or needed, nor are other activities taken into consideration.

The proactive type questions immediate assumptions, policies and mental models with the purpose of finding root causes. Future situations or mental models are not taken into consideration. The process relies on mental abstractions.

Backcasting aims at challenging mental models by creating future ideal scenarios and comparing them with current situations. It seeks to plan the changes needed to achieve such scenarios. The process relies on mental abstractions.

The experiential type is fairly similar to the proactive one, the difference lying in the attempt to challenge mental models through real life problem solving, so linking the mental abstraction with a 'hands-on' approach.

As Table 2 indicates, it is not possible to integrate triple-loop and adaptive learning. Triple-loop learning focuses on developing new methods and approaches to arrive at re-framings, whereas adaptive learning involves the search for direct solutions to immediate problems.

The discerning type aims not only to question concepts and mental models, but also to develop new processes and methodologies that could be used to avoid future problems. The process is mainly based on mental abstractions.

\begin{tabular}{lllc}
\hline Processes & & Loops & Triple \\
\cline { 2 - 4 } & \multicolumn{1}{c}{ Single } & Double & $*$ \\
\hline Adaptive & Passive & Proactive & Discerning \\
Anticipatory & Forecasting & Backcasting & Inquisitive \\
Action & Coaching & Experiential & \\
\hline
\end{tabular}

Table 2. Learning typologies according to their loops and processes

*Not applicable, since triple-loop learning focuses on developing new methods and approaches to arrive at re-framings, while adaptive learning involves the search for direct solutions to immediate problems. 
The inquisitive type aims to develop new processes and methodologies through real life problem solving, which challenges current mental models and helps re-framings.

Lower types of learning (e.g. passive learning) that do not question the underlying principles of the organization, tend to increase bureaucracy, and curtail response to internal and external stimuli. Discerning and inquisitive learning can play important roles in facilitating organizational 'metanoia' by questioning current mental models and developing new theories, methodologies and processes, such as more realistic classroom experiences when teaching sustainable development (Davis et al., 2004).

Although learning is an important part of any change process, it cannot be expected that individuals, groups or the organization would change their habits after a few days of education (Kotter, I996). Instead learning needs to be continuous to facilitate changes in the other types of mental attitudes. Initiatives that fail to change mental models and behaviours tend to produce frustration and are prone to failure (Doppelt, 2003).

\section{Consolidating New More Sustainable Mental Models}

Creativity (through cognitive and non-cognitive traits and convergent and divergent thinking synergies) can challenge Newtonian and Cartesian mental models and break through knowledge barriers. This sets the stage for individual 'Eureka' moments to be endorsed by groups, organizations, and society to foster metanoia for sustainability. These new mental models can be institutionalized and consolidated through organizational learning (especially when developing new methodologies and processes). The consolidation of new ideas starts with passive learning moving to forecasting and coaching learning; then to proactive, backcasting and experiential; and finally to discerning and inquisitive learning, as shown in Figure 6. Once the new mental models have been institutionalized and consolidated they become the established norm, whereupon new knowledge barriers need to be broached, in their turn, by creativity throughout the knowledge continuum, as depicted in Figure 7.

A note should be added; knowledge does not follow the laws of thermodynamics. Paradigms can be created, and sometimes also destroyed (or proven wrong). It is true that knowledge flows from a system with more knowledge to a system with less knowledge. Finally, entropy does not affect knowledge in the same way that it affects energy, because knowledge has the potential to not degrade, i.e. it is not directly affected by limits to growth.

\section{Creativity, 'Gaia' and Sustainability}

This section uses Lovelock's (2007) concept of 'Gaia' ${ }^{6}$ to exemplify how creativity could help to move from current unsustainable practices and mental models to more sustainable societies. Gaia proposes that the Earth is a collection of objects, including humans, that interact in self-regulating systems of climate and chemistry (Reason, 2004).

Lovelock started to 'brew'7 his concept of 'Gaia' theory in the I960s, but the theory did not appear publicly until about I970. This was Lovelock's 'Eureka' moment. Lovelock (2007) indicates that from the beginning his ideas of self-regulation were unpopular with earth and life scientists.

It took decades for Gaia theory to be partially accepted, because research evidence was needed to confirm it (Lovelock, 2007). Although some individuals rejected the idea at first, a group of scientists saw that it was, as Csikszentmihalyi (200I) indicates, a true creative meme, and not just simply bizarre. This has led to a number of authors discussing and adopting it (e.g. Do Carmo et al., 2009; Karnanin and Annila, 2009; Reason, 2004). In a search using SCHOLAR GOOGLE the term 'Gaia theory' yielded over 24,000 hits. This could be considered as group sanctioning (Csikszentmihalyi, 200I). An important step towards Gaia's adoption and its institutionalization in society was its recognition by the Amsterdam Declaration (EESP, 200I).

\footnotetext{
${ }^{6}$ The concept of 'Gaia' used in this paper is the original one posited by Lovelock (2007) and not the radical position taken by some fanatical environmentalists, and in some cases by supporters of strong sustainability.

7In this context 'brew' refers to the immersion and incubation processes discussed by McNally (I982), i.e. providing time for the ideas to come together, as one would do when brewing a good cup of coffee.
} 


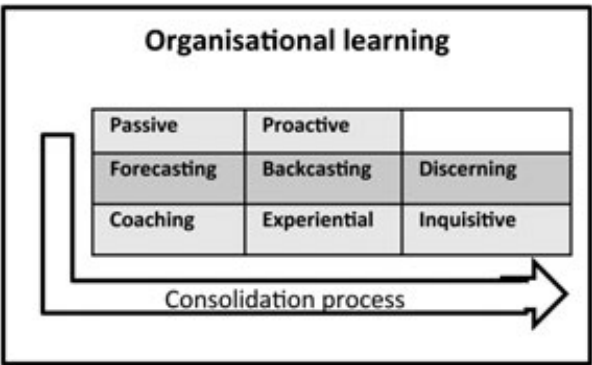

Figure 6. Consolidation of knowledge through organizational learning

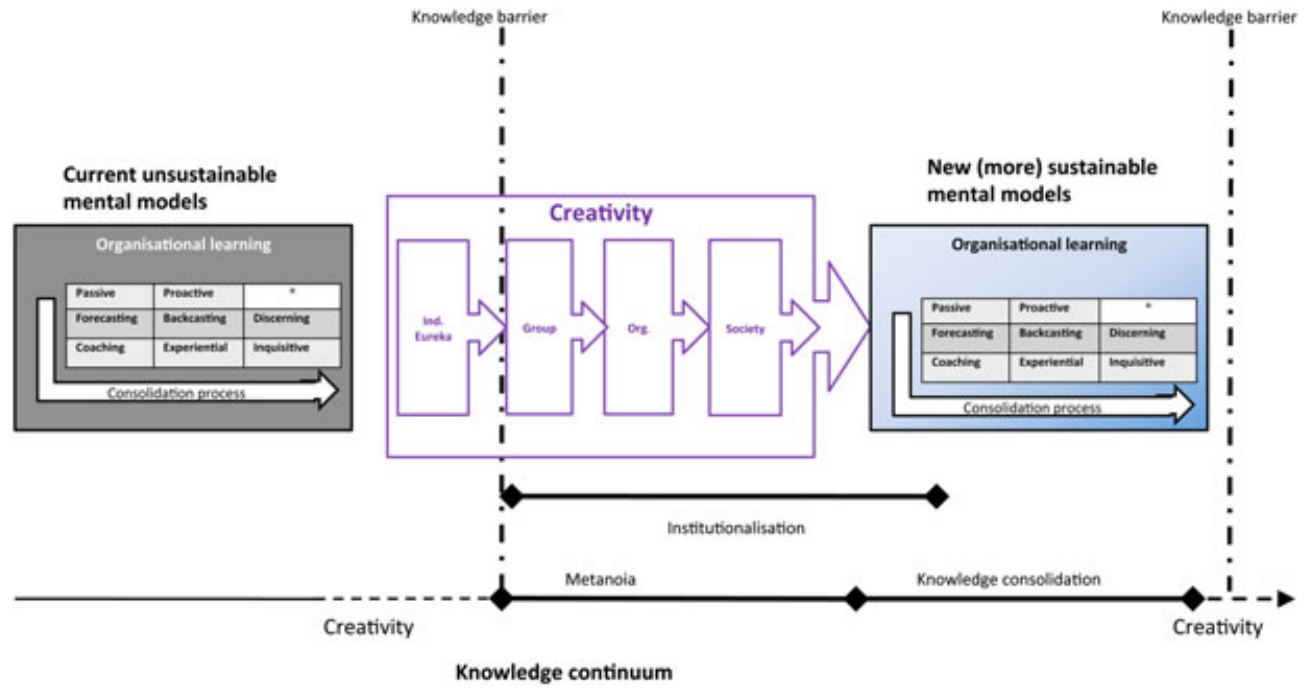

Figure 7. Creativity and organizational learning as means to generate and institutionalize new more sustainable mental models

Gaia theory offers an alternative to Newtonian/Cartesian mental models by proposing systems thinking and science, inter-relations and holistic perspectives.

As the example has shown, the creativity process (continuum) from the moment Lovelock started to think about self-regulatory systems, to his 'Eureka' moment, resulted in the Gaia theory being accepted, adopted and, to a great extent, institutionalized in some sections of society. However, a question remains: how could Gaia theory, and in turn the sustainability meme and its mental models, be further propagated, and so foster metanoia?

The answer lies in how organizational learning evolves. When a theory, or mental model, such as Gaia, is first developed, learning about it would, unavoidably, be through passive learning. For example, although the individuals involved understand it, the teaching of Gaia theory in Brazilian high schools could be considered to be Passive learning (see Do Carmo et al., 2009). However, when a theory is questioned through double-loop learning, as would take place, for example in the reflective learning of Gaia theory (Haigh, 200I), or through thermodynamics (Karnanin and Annila, 2009), then both these processes could be considered to be Proactive learning. This is shown in Figure 8, where the shaded cells on the right-hand side represent the type of learning that has taken place. The questioning of the theory to develop new processes and methodologies could lead to Discerning and Inquisitive learning.

\section{Conclusions: Fostering Sustainability Metanoia}

Much of modern education and praxis has relied on Newtonian and Cartesian mental models, which have resulted in unprecedented advances in development and industrialization with concomitant dramatic global economic and 


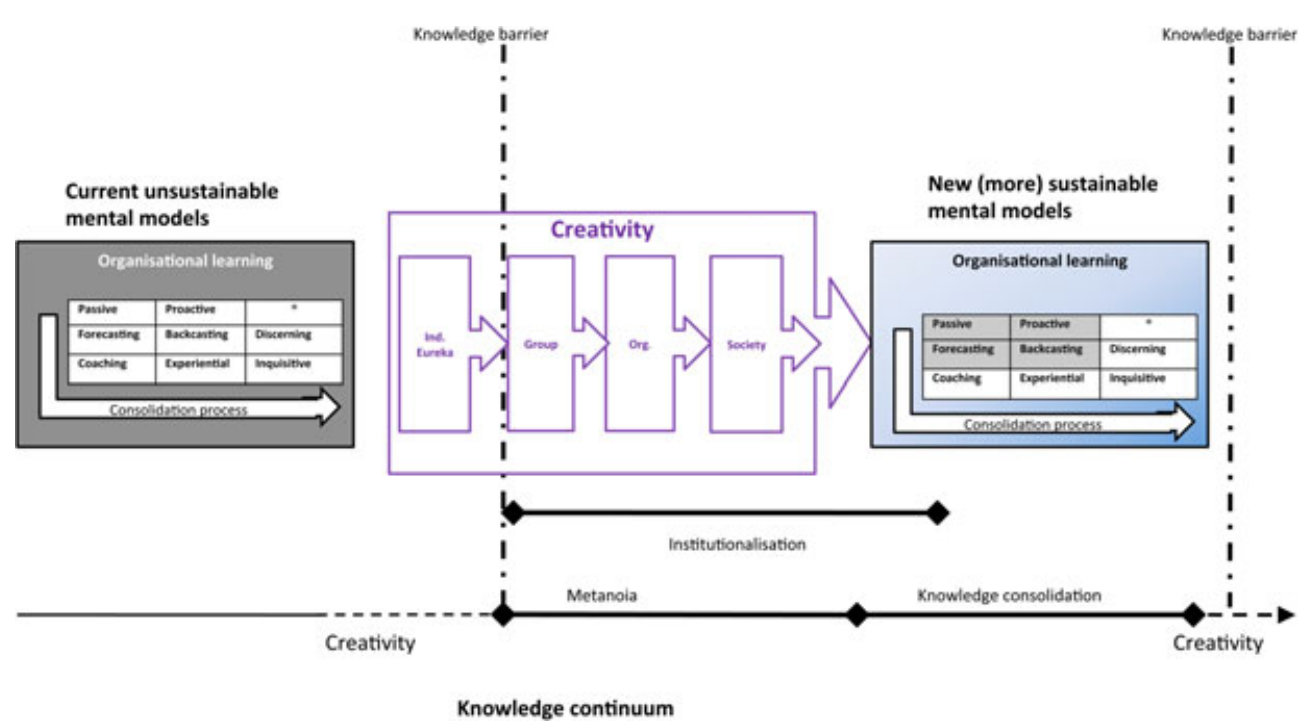

Figure 8. Creativity and organizational learning as means to illustrate the transfer and consolidation of Gaia theory

technological changes. However, they have also resulted in a civilization crisis, which confronts us with an unsustainable present and a threatened future.

We need to dispel ignorance about the impacts that development and industrialization have had, and are having, on the environment and societies if we are to move towards more sustainable societies. This can be achieved by 'unlearning' old models and providing new ones as part of the solution that actively and consciously engages in the prudent use and protection of natural resources, while safeguarding and improving the quality of life and well-being of society for this and future generations. By rejecting current mental models and synthesizing new ones, creativity can rupture knowledge barriers, demolish silo mentalities, and abrogate reductionism by fostering sustainability metanoia throughout the complex mosaic of individuals, groups, organizations, societies and their interactions.

Individual creativity synergistically links cognitive and non-cognitive traits, i.e. rationality and emotions, where the process follows related stages: immersion, incubation, illumination, explication, creative synthesis, and dissemination. Change agents play a key role in adopting new ideas or memes in the metanoia and institutionalization stages, where creativity is transferred and becomes part of the culture of groups, organizations, and society, so producing new mental models. They should facilitate discerning and inquisitive learning, ensure that the system is congruent and aligned (or that mechanisms are set in place to overcome resistance to change), and garner support for the marriage of rationality and emotions.

Creativity needs to be completed with constant organizational learning (i.e. acquiring and increasing knowledge, and creating and refining mental models), which is recognized as a key skill to achieve sustainable development. As with creativity, learning is complex and iterative with multiple feedback processes that take place between individuals, groups, organizations and society, taking into account their emotions and behaviours in relation to the system. Organizational learning, especially when developing new methodologies and processes, i.e. discerning and inquisitive learning, can help to institutionalize and consolidate new more sustainable mental models. Creativity would then challenge these new mental models, and the process would continue ad infinitum. However, some part of the system may still cling to the older paradigms for some time. A caveat is in order; change is hindered by incongruence in the attitudes and unaligned system elements.

Progress towards more sustainable societies implies that we move from reactive responses to immediate problems, towards a more proactive focus on avoiding possible future problems and prepare for potential events. This is especially the case where real problems can be turned into a learning laboratory where new theories, methodologies, and tools are developed that challenge the status quo in order to solve today's problems with tomorrow's ideas, as Gaia theory illustrates.

Fostering and supporting creativity can help to break silo mental models, by bridging the schism between rationality and emotions, as well as that between science and the arts, as was the case during the Renaissance. These 
changes in mental models and lifestyles would help to go beyond causality, mono-disciplinarity, reductionism, and over-specialization, by continuously tending towards reflective education and praxis that is systems oriented, holistic, collaborative, intra- and inter-generationally based, and interconnected.

Creativity and learning for sustainability will fall into the knowledge abyss if they cannot be transferred from individuals to groups, organizations, and finally to society. Therefore, individuals who are working on sustainable development must share their knowledge, and engage in collaboration with the different sectors of society.

Further research should be carried out on sustainability meme transfer, and on the evaluation and implementation of the organizational learning types proposed. It is hoped that this article serves to challenge and develop new competences for sustainability based on holism, transdisciplinarity, systems thinking and long-term thinking.

\section{References}

Amabile TM. I983. The Social Psychology of Creativity. Springer-Verlag: New York.

Argyris C. I977. Double loop learning in organizations. Harvard Business Review, September-October, II5-I25. doi: I0.I225/77502

Arieti S. I976. Creativity. The Magic Synthesis. Basic Books, Inc., Publishers: New York.

Bagheri A, Hjorth P. 2007. Planning for Sustainable Development: a Paradigm Shift Towards a Process-Based Approach. Sustainable Development I5: $83-96$.

Basadur M, Graen GB, Green SG. I982. Training in creative problem-solving: effects on ideation and problem finding and solving in an industrial research organization. Organizational Behavior and Human Performance 30: 4I-70. doi: 10.1016/0030-5073(82)90233-I

Basadur M, Graen GB, Scandura TA. I986. Training effects on attitudes toward divergent-thinking among manufacturing engineers. The Journal of Applied Psychology 7I: 6I6-6I7. doi: 10.1037/002I-9010.7I.4.6I2

Bloom B, Englehart M, Furst E, Hill W, Krathwohl D. I956. Taxonomy of Educational Objectives: the Classification of Educational Goals. Handbook I: Cognitive Domain. Longmans, Green: New York, Toronto.

Brown A. 2005. J. D. Bernal. The Sage of Science. Oxford University Press: oxford.

Brown VA, Harris JA, Russel JY. (Eds). 20I0. Tackling Wicked Problems. Through the Transdisciplinary Imagination. Earthscan Publications Ltd.: London.

Burke J. 2000. The Knowledge Web (Ist ed.n). Touchstone: New York.

Carley M, Christie I. 2000. Managing Sustainable Development, (2nd edn.). Earthscan Publications Ltd.: London.

Clarke S, Roome N. 1999. Sustainable Business: Learning - action networks as organizational assets. Business Strategy and the Environment 8: 296-310. doi: 10.1002/(SICI)I099-0836(I99909/10)8:5<296::AID-BSE212>3.0.CO;2-N

Cortese AD. 2003. The critical role of higher education in creating a sustainable future. Planning for Higher Education 3I(3): I5-22.

Csikszentmihalyi M. 200I. A systems perspective on creativity. In: Henry J (Ed.) Creative Management, (2nd edn). Sage Publications Ltd.: London.

Davis SA, Edmister JH, Sullivan K, West CK. 2004. Educating sustainable societies for the twenty-first century. International Journal of Sustainability in Higher Education 4(2): 169-179. doi: 10.1108/14676370310467177

Dawkins R. 1978. The Selfish Gene. Oxford University Press: London.

Do Carmo RS, Nunes-Nieto NF, El-Hani CN. 2009. Gaia theory in Brazilian high school biology textbooks. Science Education I8(3-4): 469-50I. doi: $10.1007 /$ siII9I-008-9I49-3

Doppelt B. 2003. Leading change toward sustainability. A change-management guide for business, government and civil society. Greenleaf Publishing: Sheffield.

Dunphy D, Griffiths A, Benn S. 2003. Organizational Change for Corporate Sustainability. Routledge: London.

EESP. 200I. The Amsterdam Declaration Retrieved 6 July, 20I0, from http://www.essp.org/index.php?id=4I

Gabriel Y. 200I. Psychodynamics, psychoanalysis, and organizations. In: Henry J (Ed.), Creative Management, (2nd edn.). Sage Publications Ltd.: London.

Gill R. 2003. Change management - or change leadership? Journal of Change Management 3(4): 307-3I8.

Haberl H, Fischer-Kowalski M, Krausmann F, Martinez-Alier J, Winiwarter V. 20II. A Socio-metabolic Transition towards Sustainability? Challenges for Another Great Transformation. Sustainable Development I9: I-I4. doi: I0.1002/sd.4IO

Haigh MJ. 200I. Constructing Gaia: using journals to foster reflective learning. Journal of Geography in Higher Education 25(2): 167-I89. doi: 10.1080/03098260120067637

Hailey J. I998. Management education for sustainable development. Sustainable Development 6: 40-48.

Henry J (Ed.) 200I. Creative Management, (2nd edn). Sage Publications Ltd.: London.

Jensen MC. I993. The Modern Industrial Revolution, Exit, and the Failure of Internal Control Systems. Journal of Finance 48(3). doi: Io.IIII/ j.1745-6622.2010.00260.x

Karnanin M, Annila A. 2009. Gaia again. Biosystems 95(I): 82-87.

Kaufmann G. 200I. Creativity and problem solving. In Henry J (Ed.) Creative Management, (2nd edn.). Sage Publications Ltd.: London.

Ketola T. 2009. Pre-Morphean Paradigm - An Alternative to Modern and Post-Modern Paradigms of Corporate Sustainability. Sustainable Development I7: II4-I26. doi: I0.I002/sd.406

Kotter JP. I996. Leading Change. Boston: Harvard Business School Press. 
Kuhn TS. I970. The Structure of Scientific Revolutions (2nd edn). The University of Chicago Press: Chicago.

Lessard DR, Amsden AH. I996. The Multinational Enterprise as a Learning Organization. Paper presented at George Washington University as part of the Institute for Global Management Research lecture series, April I996.

Lovelock J. 2007. The Revenge of Gaia. Penguin Group: London.

Lozano R. 2006. A tool for a Graphical Assessment of Sustainability in Universities (GASU). Journal of Cleaner Production I4(9-II): 963-972.

Lozano R. 2008a. Developing collaborative and sustainable organisations. Journal of Cleaner Production I6(4): 499-509. doi: I0.I0I6/j. jclepro.2007.01.002

Lozano R. 2008b. Developing collaborative and sustainable organisations. Journal of Cleaner Production I6(4), March 2008, ISSN: $0959-6526$, doi: го.ıо16/j.jclepro.2007.01.002.

Luthans F. 2002. Organizational Behavior. McGraw-Hill: New York.

Mayer RE. I989. Cognitive views of creativity: creative teaching for creative learning. Contemporary Educational Psychology I4: 203-2II. doi: Iо.1016/036I-476X(89)900I0-6

McIntosh M, Leipziger D, Jones K. I998. Corporate Citizenship. Successful Strategies for Responsible Companies. Financial Times, Pitman Publishing: London.

McNally C. I982. The Experience of Being Sensitive. Doctoral dissertation, Center for Humanistic Studies, Detroit, MI.

Miller D. I990. The Icarus Paradox. How Exceptional Companies Bring About Their Own Downfall. HarperBusiness: New York, U.S.A..

Mohammed S, Dumville BC. 200I. Team mental models in a team knowledge framework: expanding theory and measurement across disciplinary boundaries. Journal of Organizational Behavior 22: 89-106. doi: 10.1002/job.86

Nonaka I, Takeuchi H. 200I. Organizational knowledge creation. In: Henry J, (Ed.) Creative management (2nd edn). Sage Publications Ltd.: London.

Orr DW. 1992. Ecological Literacy. State University of New York: New York.

Penrose ET. 1959. The Theory of the Growth of the Firm. Basil Blackwell: Oxford.

Posch A, Steiner G. 2006. Integrating research and teaching on innovation for sustainable development. International Journal of Sustainability in Higher Education 7(3): 276-292. doi: 10.1108/14676370610677847

Reason P. 2004. Education for Ecology: Science, Aesthetics, Spirit and Ceremony. School of Management, University of Bath: Bath.

Reid D. I995. Sustainable Development. An Introductory Guide (Ist edn.), Earthscan Publications Ltd.: London.

Rogers EM. I995. Diffusion of Innovations (4th edn). New York: Free Press.

Rosner WJ. I995. Mental models for sustainability. Journal of Cleaner Production 3(I-2): I07-I2I. doi: I0.1016/0959-6526(95)00057-L

Schein EH. I969. The mechanisms of change. In Bennis WG, Benne KD, Chin R (Eds.) The Planning of Change (2nd edn). Holt, Rinehart and Winston, Inc.: New York.

Senge PM. 1999. The Fifth Discipline. The Art \& Practice of the Learning Organization. Random House Business Books: London.

Shaw MP. I989. The Eureka process: a structure for the creative experience in science and engineering. Creativity Research Journal 2: $286-298$. doi: $10.1080 / 10400418909534325$

Sherry L. 2003. Sustainability of Innovations. Journal of Interactive Learning Research 13(3): 209-236.

Sternberg RJ. 2006. The nature of creativity. Creativity Research Journal I8(I): 87-98. doi: I0.I207/si5326934crj180I_IO

Sternberg RJ, Lubart T. I999. The concept of creativity: prospects and paradigms. In: Sternberg RJ, Lubart T (Eds). Handbook of Creativity. Cambridge University Press: Cambridge.

van de Ven AH, Polley DE, Garud R, Venkataraman S. I999. The Innovation Journey. Oxford University Press: Oxford.

Waddel S. 2005. Societal Learning and Change. How Governments, Business and Civil Society are Creating Solutions to Complex Multi-stakeholder Problems. Greenleaf Publishing Ltd.: Sheffield.

WCED. I987. Our Common Future (Ist edn). Oxford University Press: Oxford.

Woodman RW, Sawyer JE, Griffin RW. I993. Toward a theory of organizational creativity. Academy of Management Review I8(2): 293-32I. doi: I0.2307/25876I

Zadek S. 2004. The path to corporate responsibility. Harvard Business Review 82(I2): I25-I32. 